\title{
The Absorption and Magnetic Circular Dichroism Spectra of Matrix-Isolated $\mathrm{Os}^{18} \mathrm{O}_{4}$ and $\mathrm{Os}^{16} \mathrm{O}_{4}$
}

\author{
ROGER GRINTER \\ Schonl of Chemical Sciences, University of East Anglia, Norwic NR4 7TJ, England
}

AND

RICHARD L. ZIMMERMAN AND THOMAS M. DUNN

Department of Chemistry, University of Michigan, Ann Arbor, Michigan 48109

\begin{abstract}
Matrix absorption and magnetic circular dichroism studies on $\mathrm{Os}^{16} \mathrm{O}_{4}$ and $\mathrm{Os}^{18} \mathrm{O}_{4}$ have been carried out to clarify the number of electronic transitions present in the region. The spectra show that the irregular vibrational structure in the ${ }^{16} \mathrm{O}$ species with its onset at $\sim 276 \mathrm{~nm}$ is perfectly regular in the ${ }^{18} \mathrm{O}$ compound. The system is, therefore, interpreted as a single electronic system analogous to that observed in the permanganate ion. The Raman spectrum of $\mathrm{Os}^{16} \mathrm{O}_{4}$ single crystal has also been obtained.
\end{abstract}

\section{INTRODUCTION}

Despite considerable effort, the electronic spectrum of osmium tetroxide has not yet been thoroughly assigned. Absorption spectra of both gas phase $(1,2)$ and solution samples (3) have been reported. More recently, magnetic circular dichroism (mcd) spectra of the vapor (4) and of matrix-isolated samples (5) have been measured but doubts remain, even with respect to fundamental questions such as how many electronic band systems contribute to the structured absorption spectrum between about 31000 and $50000 \mathrm{~cm}^{-1}$. In particular, there is for $\mathrm{Os}^{16} \mathrm{O}_{4}$ a region of complex vibrational structure between 35000 and $39000 \mathrm{~cm}^{-1}$ which might belong to an electronic state distinct from those responsible for the absorption bands in the regions 31000-35000 and $40000-50000 \mathrm{~cm}^{-1}(4,5)$. Additionally, any consideration of the vibrational structure is complicated by the fact that a significant Jahn-Teller (J-T) effect, such as that observed in the ${ }^{1} T_{2}-{ }^{1} A_{1}$ electronic system of the permanganate ion (6) and in the lowest energy singlet transition ${ }^{1} T_{1} \leftarrow{ }^{1} A_{1}$ of $\mathrm{OsO}_{4}$ in its two-photon spectrum (7), may be present.

\section{EXPERIMENTAL DETAILS}

We have measured the absorption and mcd spectra of both the ${ }^{16} \mathrm{O}$ and ${ }^{18} \mathrm{O}$ isotopic species of $\mathrm{OsO}_{4}$ in argon matrices at temperatures of $5 \mathrm{~K}$ and below. Our results are summarized in Table $I$ and in Figs. 1 and 2. Some remarks are appropriate with respect to the figures. 
TABLE I

Absorption Band Positions ( $\mathrm{cm}^{-1}$ )

\begin{tabular}{|c|c|c|c|c|}
\hline & $\lambda(\mathrm{nm})$ & $\bar{v}\left(\operatorname{vac} \mathrm{cm}^{-1}\right)$ & $\lambda(\mathrm{nm})$ & $\bar{v}\left(\operatorname{vac} \mathrm{cm}^{-1}\right)$ \\
\hline $\begin{array}{l}a \\
a^{\prime}\end{array}$ & $\begin{array}{l}319.0 \\
316.0\end{array}$ & $\begin{array}{l}31339 \\
31636\end{array}$ & $\begin{array}{l}318.8 \\
316.2\end{array}$ & $\begin{array}{l}31358 \\
31616\end{array}$ \\
\hline $\begin{array}{l}b \\
b^{\prime} \\
b^{\prime \prime}\end{array}$ & $\begin{array}{l}310.8 \\
308.4 \\
307.8\end{array}$ & $\begin{array}{l}32166 \\
32416 \\
32479\end{array}$ & $\begin{array}{l}311.0 \\
308.5\end{array}$ & $\begin{array}{l}32145 \\
32405\end{array}$ \\
\hline $\begin{array}{l}c \\
c \\
c^{\prime}\end{array}$ & $\begin{array}{l}302.8 \\
300.6 \\
299.8\end{array}$ & $\begin{array}{l}33015 \\
33257 \\
33346\end{array}$ & $\begin{array}{l}303.4 \\
301.1\end{array}$ & $\begin{array}{l}32950 \\
33201\end{array}$ \\
\hline $\begin{array}{l}d \\
d^{\prime} \\
d^{\prime \prime}\end{array}$ & $\begin{array}{l}295.4 \\
293.1 \\
292.2\end{array}$ & $\begin{array}{l}33843 \\
34108 \\
34213\end{array}$ & $\begin{array}{l}296.4 \\
294.0\end{array}$ & $\begin{array}{l}33740 \\
34003\end{array}$ \\
\hline $\begin{array}{l}e \\
e^{\prime} \\
e^{\prime \prime}\end{array}$ & $\begin{array}{l}288.3 \\
286.1 \\
285.1\end{array}$ & $\begin{array}{l}34676 \\
34942 \\
35065\end{array}$ & $\begin{array}{l}289.6 \\
287.6\end{array}$ & $\begin{array}{l}34529 \\
34760\end{array}$ \\
\hline $\begin{array}{l}f \\
f^{\prime}\end{array}$ & $\begin{array}{l}281.6 \\
278.3\end{array}$ & $\begin{array}{l}35500 \\
35921\end{array}$ & 283.4 & 35275 \\
\hline$\stackrel{g}{g}$ & $\begin{array}{l}276.0 \\
271.8\end{array}$ & $\begin{array}{l}36221 \\
36780\end{array}$ & 277.2 & 36064 \\
\hline $\mathrm{h}$ & 270.0 & 37026 & 271.5 & 36821 \\
\hline i & & & 266.0 & 37582 \\
\hline $\mathrm{p}$ & 265.0 & 37724 & $\begin{array}{l}265.1 \\
264.0\end{array}$ & $\begin{array}{l}37710 \\
37867\end{array}$ \\
\hline$j$ & & & 260.6 & 38361 \\
\hline$\stackrel{q}{q}$. & $\begin{array}{l}258.8 \\
257.5\end{array}$ & $\begin{array}{l}38628 \\
38823\end{array}$ & $\begin{array}{l}258.9 \\
257.4\end{array}$ & $\begin{array}{l}38613 \\
38838\end{array}$ \\
\hline$k$ & & & 255.4 & 39142 \\
\hline $\begin{array}{l}r \\
r\end{array}$ & $\begin{array}{l}253.4 \\
252.0\end{array}$ & $\begin{array}{l}39451 \\
39670\end{array}$ & $\begin{array}{l}253.5 \\
252.3\end{array}$ & $\begin{array}{l}39435 \\
29623\end{array}$ \\
\hline $\begin{array}{l}\text { s } \\
s^{\prime}\end{array}$ & $\begin{array}{l}247.9 \\
246.6\end{array}$ & $\begin{array}{l}40326 \\
40539\end{array}$ & $\begin{array}{l}248.5 \\
247.4\end{array}$ & $\begin{array}{l}40229 \\
40408\end{array}$ \\
\hline $\begin{array}{l}t \\
t^{\prime}\end{array}$ & $\begin{array}{l}242.8 \\
241.7\end{array}$ & $\begin{array}{l}41173 \\
41361\end{array}$ & $\begin{array}{l}243.5 \\
242.5\end{array}$ & $\begin{array}{l}41055 \\
41224\end{array}$ \\
\hline $\begin{array}{l}u \\
u^{\prime}\end{array}$ & $\begin{array}{l}238.0 \\
237.0\end{array}$ & $\begin{array}{l}42004 \\
42181\end{array}$ & $\begin{array}{l}238.8 \\
238.0\end{array}$ & $\begin{array}{l}41863 \\
42003\end{array}$ \\
\hline $\begin{array}{l}v \\
v^{\prime}\end{array}$ & $\begin{array}{l}233.2 \\
232.4\end{array}$ & $\begin{array}{l}42868 \\
43016\end{array}$ & $\begin{array}{l}234.4 \\
233.6\end{array}$ & $\begin{array}{l}42649 \\
42795\end{array}$ \\
\hline $\begin{array}{l}w \\
w^{\prime}\end{array}$ & 228.5 & 43750 & $\begin{array}{l}230.0 \\
229.4\end{array}$ & $\begin{array}{l}43464 \\
43578\end{array}$ \\
\hline $\begin{array}{l}x \\
x^{\prime}\end{array}$ & 224.0 & 44629 & $\begin{array}{l}226.0 \\
225.4\end{array}$ & $\begin{array}{l}44234 \\
44351\end{array}$ \\
\hline $\begin{array}{l}y \\
y^{\prime}\end{array}$ & 219.4 & 45564 & $\begin{array}{l}222.0 \\
221.0\end{array}$ & $\begin{array}{l}45031 \\
45234\end{array}$ \\
\hline $\begin{array}{l}z \\
z\end{array}$ & 216.0 & 46281 & $\begin{array}{l}218.0 \\
217.0\end{array}$ & $\begin{array}{l}45857 \\
46068\end{array}$ \\
\hline
\end{tabular}

(a) The weak structure on the low-energy side of the $\mathrm{Os}^{16} \mathrm{O}_{4}$ mod spectrum (Fig. 2) is noise. In general this spectrum is slightly noisier than its $\mathrm{Os}^{18} \mathrm{O}_{4}$ counterpart.

(b) The arrows in Fig. 1 are used to show that, despite the letter indicator, the band(s) are not necessarily the corresponding ones in the two separate species.

It should be noted that the frequencies given in Table I correspond to the maxima 


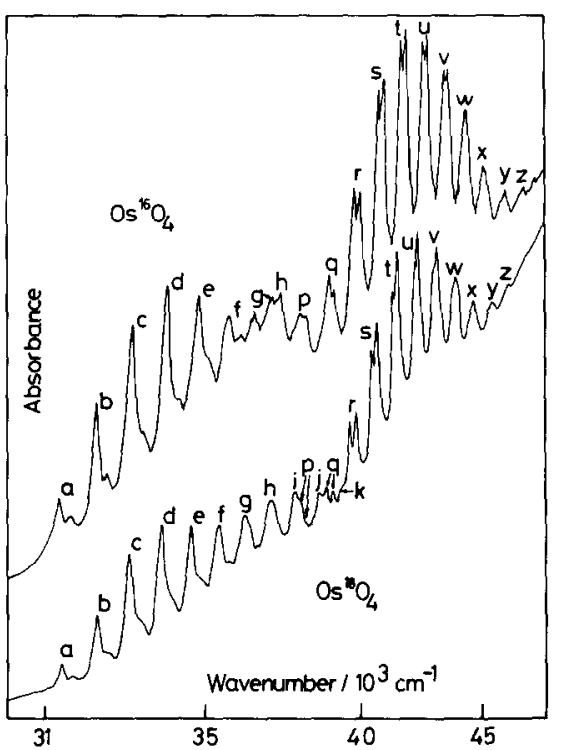

FIG. 1. Absorption spectrum of $\mathrm{OsO}_{4}$.

of the bands of the main progression and that, in the case of $\mathrm{Os}^{16} \mathrm{O}_{4}$, these were recorded photographically on a Bausch and Lomb $1.5-\mathrm{m}$ spectrograph using an iron hollow-cathode lamp to provide a wavelength standard. This was not done with the $\mathrm{Os}^{18} \mathrm{O}_{4}$ spectra, which were obtained only upon a Cary spectrophotometer; both the

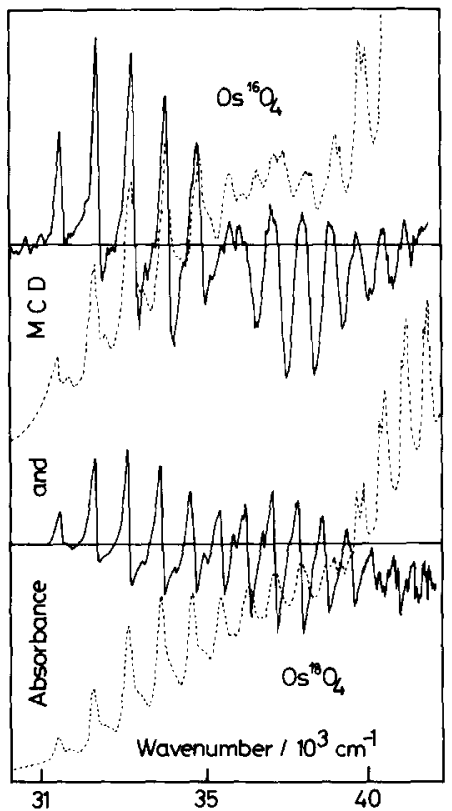

FIG. 2. Magnetic circular dichroism spectra of $\mathrm{OsO}_{4}$. 
absorption spectra given in Fig. 1 were obtained in this way. Nonetheless, an independent comparison of the Cary results in the case of the $\mathrm{Os}^{16} \mathrm{O}_{4}$ with those obtained from the much more accurate photographic standards revealed differences of less than $0.5 \AA$ for the first six bands in the main progression $(a \ldots f)$.

The photographically determined spectra also indicated clearly a splitting of the weaker progression in $\mathrm{Os}^{16} \mathrm{O}_{4}$ commencing at band $b^{\prime}$ (see Table I) and continuing through the system.

A survey of the literature concerning the Raman spectrum of osmium tetroxide has some unsatisfactory features, particularly the frequencies of $\nu_{2}$ and $\nu_{4}$. There are also some small differences between gas phase and solid state which, even though small, are important, especially when one realizes that, in tetrahedral molecules of this kind, $\nu_{1}$ is usually less than $\nu_{3}$ and $\nu_{2}$ is usually less than $\nu_{4}$, whereas exactly the opposite has been found, for both $\nu_{1}$ and $\nu_{3}$, in this case. Accordingly, a single crystal of osmium tetroxide $\left({ }^{16} \mathrm{O}\right)$ was grown by temperature gradient diffusion methods, and the Raman spectrum, obtained using both helium-neon and argon ion (5145 $\AA)$ laser radiation, was analyzed. The results confirm that $\nu_{1}$ is indeed greater than $\nu_{3}$ and that $\nu_{2}$ is greater than $\nu_{4}$, in agreement with the vapor results $(8,10,11)$, liquid (9), solution (10) and other solid-state studies (9). In addition, however, we were able to obtain the phonon modes of the crystal and the results of this analysis are presented in Table II.

\section{DISCUSSION}

Figure 1 shows that there are quite significant differences between the absorption spectra of the two compounds and that, in particular, the complex region of the $\mathrm{Os}^{16} \mathrm{O}_{4}$ spectrum (bands $f, g$, and $h$ ) does not have an obvious counterpart in the

TABLE II

Raman Spectrum of $\mathrm{Os}^{16} \mathrm{O}_{4}$ Single Crystal

\begin{tabular}{|c|c|}
\hline $\begin{array}{c}\text { Displacement } \\
\Delta v\left(\mathrm{~cm}^{-1}\right)\end{array}$ & Assignment \\
\hline 337 & \multirow{3}{*}{ Phonon } \\
\hline 55$\}$ & \\
\hline 104$\}$ & \\
\hline 327$)$ & \multirow{3}{*}{$t_{2}\left(v_{4}\right)$} \\
\hline 329$\}$ & \\
\hline 331$)$ & \\
\hline 341 & \multirow{2}{*}{$e\left(v_{2}\right)$} \\
\hline & \\
\hline 945$)$ & \multirow[b]{2}{*}{$t_{2}\left(w_{3}\right)$} \\
\hline 948$\}$ & \\
\hline 964 & $a_{1}\left(w_{1}\right)$ \\
\hline
\end{tabular}


$\mathrm{Os}^{18} \mathrm{O}_{4}$ spectrum. The structure between bands $i$ and $r$ of that latter spectrum is somewhat more complicated than in other regions, but it is not difficult to deduce that bands $i, j$, and $k$ form a continuation of the progression associated with the first electronic absorption band (with its origin at $31339 \mathrm{~cm}^{-1}$ ). The doublet $q$ clearly forms part of the progression $r, s, t \ldots$, but it is not immediately obvious from the figure whether $q$ is, indeed, the origin of the higher energy system. A comparison of the main progression frequency in both systems indicates that the zero-point shift of the origin should not be markedly different in the two cases and, as can be seen from Table I, the origin of the first ${ }^{18} \mathrm{O}$ system is approximately $20 \mathrm{~cm}^{-1}$ to higher frequencies of the corresponding ${ }^{16} \mathrm{O}$ system. In fact, if one uses the approximation that the upper-state frequencies are roughly 0.9 of the lower-state frequencies (see below), a zero-point shift of about $16 \mathrm{~cm}^{-1}$ in the observed direction is predicted.

Because there is complete consistency between the frequency measurements of the ${ }^{18} \mathrm{O}$ and ${ }^{16} \mathrm{O}$ systems (having been both done on the same instrument, etc.), the two sets of frequencies may be compared directly. This comparison quickly indicates that the band $q$ of the ${ }^{18} \mathrm{O}$ species is ca $10 \mathrm{~cm}^{-1}$ to lower frequency compared with the ${ }^{16} \mathrm{O}$ species. Since exactly the opposite should be expected for the origin band, and since one less quantum of the main progression interval will accomplish this objective almost exactly, the origin of the highest energy system has been placed approximately at the location of band $p$. It is also clear from the ${ }^{16} \mathrm{O}$ species that the band labeled $p$ is principally a component of the lower-energy transition, because its intensity is far too high to be associated with the origin of the higher energy transition. It must be presumed that this origin underlies the observed band $p$. The shoulders representing band $p$ in the case of the ${ }^{18} \mathrm{O}$ species are likewise not to be identified with the precise origin of this system, since the first quantum would then be approximately $910 \mathrm{~cm}^{-1}$ (and $900 \mathrm{~cm}^{-1}$ for the ${ }^{16} \mathrm{O}$ case), which is somewhat larger than the progression interval in both cases.

With this assignment and the recognition that there will therefore be no bands of the high-energy system at lower frequencies than this, it seems safe to say that the suggestions made originally $(4,5)$, that there is an additional system in this area, can be discounted. There is absolutely no trace of this "system" in the ${ }^{18} \mathrm{O}$ spectrum. We have tentatively ascribed the somewhat irregular nature of the ${ }^{16} \mathrm{O}$ bands to a case of Fermi resonance. In fact, with the kinds of frequencies known from the ground state, it is perhaps surprising that the spectrum is as regular as it appears.

The mod spectra, Fig. 2, appear to confirm the above conclusions. Both spectra, but more particularly that of the $\mathrm{Os}^{16} \mathrm{O}_{4}$, show the overall $A$-term structure of the long-wavelength band, which is also seen clearly in the solution spectrum (3). Furthermore, the individual vibration bands of each progression, apart from the interruption at approximately $35500 \mathrm{~cm}^{-1}$ in the $\mathrm{Os}^{16} \mathrm{O}_{4}$ case, show a rather smooth development as we proceed through the band from lower to higher energies. For the ${ }^{16} \mathrm{O}$ material this has been remarked upon before (5), and compared with the very similar situation in permanganate (6). The characteristic structure of the mcd spectrum of the first electronic system appears to continue well into the second system, its regularity giving the impression that the mcd observed, even well into the second system, is almost entirely due to the first band system. This will be discussed further below. 
Before discussing the significance of these results, there are some other features of these spectra which deserve comment. First, it will be noted that the onset of absorption in both isotopic systems at ca $31000 \mathrm{~cm}^{-1}$ is not at all abrupt, even when due regard is paid to the effect of matrix scattering. The spectrographic analysis of the ${ }^{16} \mathrm{O}$ species does, indeed, indicate at least two very weak bands on the low-frequency side of band $a$, one with a separation of approximately $330 \mathrm{~cm}^{-1}$ from $a$ and the other, somewhat broader and weaker, about $1000 \mathrm{~cm}^{-1}$ to low energies of $a$. These bands seem to be too far $\left(\sim 3000 \mathrm{~cm}^{-1}\right)$ from the origin of the ${ }^{1} T_{1} \leftarrow{ }^{1} A_{1}$ system found in the twophoton study (7) to be associated with that system, and we consider it more likely that they are one of the triplet systems which must be in the region and which previous authors observed (2).

Second, a comparison has been made (6) between this band system and that of the green system of $\mathrm{MnO}_{4}^{-}$ion. To be sure, there are similarities but there are also some considerable differences, among which the most important is undoubtedly a difference in the Franck-Condon intensity distribution. When the background due to scattering, and the effects of the higher-energy absorption system are subtracted, it is quite clear that the intensity maximum is in band $d$-as can, in fact, even without subtraction, be noted in both cases from Fig. 1 .

There is also the progression $a^{\prime}, b^{\prime}, \ldots$, which is very similar to the permanganate case, but this secondary progression in osmium tetroxide also shows significant differences. Thus, the permanganate progression, which is presumably based upon a vibronic origin with one quantum with $\nu_{2}(e)$ superimposed on the electronic origin, is not observed to increase significantly in linewidth or to split with increasing numbers of quanta. Even after one quantum of the main progression-forming frequency $\left(b^{\prime}\right)$, this progression is already significantly split into two components about $60 \mathrm{~cm}^{-1}$ apart. This splitting increases steadily until it is about $120 \mathrm{~cm}^{-1}$ in the band $g^{\prime}$. Although it is difficult to measure precisely, the splitting interval does not appear to change significantly after band $d^{\prime}$, but the incomplete resolution makes it difficult to decide this issue with certainty. The source of the doubling of the vibronically allowed component is tentatively ascribed to the presence of both $\nu_{2}$ and $\nu_{4}$ in this spectrum. These two fundamentals have almost identical frequencies in the ground state, and it seems possible that this "coincidence" might persist for the excited state.

Another way in which the system in osmium tetroxide differs somewhat from that of permanganate is in the linewidth of the members of the main progression. The fact that the linewidth increases significantly with the number of vibrational quanta along this progression is somewhat obscured by the approximately linear wavelength scale used in Fig. 1. In fact, the linewidth at half the absorption height at the origin is about $145 \mathrm{~cm}^{-1}$; this rapidly increases to about $250 \mathrm{~cm}^{-1}$ for band $b$ and about $350 \mathrm{~cm}^{-1}$ for band $c$, reaching about $325 \mathrm{~cm}^{-1}$ for band $d$ and about $375 \mathrm{~cm}^{-1}$ for band $e$. After this point the blending of the low-frequency component of the second progression with the stronger (main) progression makes it difficult to obtain accurate linewidths, but the trend is obvious, even from Fig. 1. The permanganate spectrum also shows an increase in linewidth along the members of the progression, but not as large in magnitude as this. The osmium tetroxide vapor spectrum also shows a significant increase in bandwidth along the members of the main progression. These differences may well have their origins in the magnitude of the Jahn-Teller $D$ parameter 
which has been tentatively given a value (7) in $\mathrm{OsO}_{4}$ which is about a factor of two larger than for $\mathrm{MnO}_{4}^{-}(6)$.

In the gas phase the presence of hot bands (of $\nu_{2}$ and $\nu_{4}$ ) could have been a source of the very irregular vibrational intervals found by Wells et al. (2), but at a temperature of less than $5 \mathrm{~K}$ this explanation is no longer possible. It is worth noting, therefore, that this irregular character persists in the argon matrix, particularly the long interval from $b$ to $c\left(849 \mathrm{~cm}^{-1}\right)$ compared with $827 \mathrm{~cm}^{-1}$ for the interval from $a$ to $b$. The corresponding values for the vapor are 862 and 838 ; in both cases the third interval falls back to a much smaller value than for the second interval. We have no simple explanation for this situation, and we suspect that its origin is quite complex. The possibility that a Fermi resonance has shifted band $c$ to somewhat higher frequencies seems unlikely at first, since it implies that the coincidence persists in both the gas phase and in the matrix-isolated state. There is, however, a very unusual shift of equivalent bands measured in the gas phase and in matrix systems; band $c$ is maximally shifted by $44 \mathrm{~cm}^{-1}$ (matrix-isolated frequency lower than the gas-phase frequency), while this difference falls to ca 0 at band $g$. This irregularity does suggest Fermi resonance as the origin of the shift, but there is no easy way to decide this issue.

Petit et al. (3) have reported a study of $\mathrm{d}^{0} \mathrm{oxy}$ - and thioanions, including osmium tetroxide, in which they compared experimental mod spectra with the predictions of a molecular orbital model (12). As far as the sign of the mod signal is concerned, the results suggested that for all the compounds investigated the assignment of the first three electronic bands should be to states, all of $T_{2}$ symmetry, arising from the orbital transitions $t_{1} \rightarrow 2 e, t_{1} \rightarrow 4 t_{2}$, and $3 t_{2} \rightarrow 2 e$, in order of increasing energy. For the first band this assignment is well substantiated both qualitatively and quantitatively, and appears to be generally accepted. However, since $2 e$ should be lower in energy than $4 t_{2}$ by $\Delta$, the ligand field splitting, the assignment of the two higher energy bands was thought by Petit and his co-workers to be energetically unrealistic. They therefore reversed the order of these two states and attributed the discrepancy between theory and experiment to inaccuracies in the wavefunctions (12) used to calculate the mcd signs. In the light of that work Barton et al. (5) assigned the $3 t_{2} \rightarrow 2 e$ transition to a band lying between the two major band systems in $\mathrm{Os}^{16} \mathrm{O}_{4}$; a band the existence of which now appears to be very unlikely. Quested et al. (4) also suggested the possibility of a further electronic band in this region, the idea being particularly attractive in view of the complex structure seen in the $\mathrm{Os}^{16} \mathrm{O}_{4}$ spectrum in the region $35000-38000 \mathrm{~cm}^{-1}$.

Thus, although the $t_{1} \rightarrow 2 e$ assignment of the long-wavelength absorption band is quite secure, considerable doubts remain concerning the higher-energy region of the spectrum. The important experimental results of the present study are that there is no other allowed transition between the two major features of the $\mathrm{OsO}_{4}$ spectrum, and that the mcd under the second system is much weaker than that under the first.

As Petit $e t$ al. (3) pointed out, the positive $A$ term associated with the second band of the $\mathrm{OsO}_{4}$ spectrum is evidence in favor of the $t_{1} \rightarrow 4 t_{2}$ assignment for it. Furthermore their expressions (3) for the angular momentum of the $t_{1} \rightarrow 4 t_{2}$ excited state show that small values of this parameter are readily obtained, in agreement with our experimental results. However, where a strong J-T effect is possible, arguments based 
upon the magnitude of the mod signal of a particular vibronic band could go badly astray (13). In the case of the permanganate ion Cox et al. (6) found that the magnitude of $A / D$ for the vibrational lines of the ${ }^{1} T_{2} \rightarrow{ }^{\prime} A_{1}$ charge-transfer band fell off, to be replaced by an increasing value of $B$, on moving along the progression to higher energies. This behaviour could be quantitatively interpreted in terms of a J-T effect. Barton et al. (5) showed that the vibrational structure of the first $\left(t_{1} \rightarrow 2 e\right)$ band of matrix-isolated $\mathrm{OsO}_{4}$ conformed to a remarkably similar pattern. It is unfortunate that no such analysis of the mcd of the second $\mathrm{OsO}_{4}$ absorption band is possible. The assignment of that band, therefore, remains uncertain.

Finally, we comment upon the minor vibrational features seen in the bands. For both compounds and in both electronic bands splittings are observed. In the longwavelength system a small feature associated with an $\operatorname{mcd} A$ term appears to higher frequencies of the major features in the early part of the progression. Exactly the same phenomenon is seen in the low-temperature $\mathrm{MnO}_{4}^{-}$spectrum (6). Interestingly, while the separation between the major and minor peaks of the progression appears to be effectively constant in $\mathrm{Os}^{18} \mathrm{O}_{4}$, the gap opens quickly in $\mathrm{Os}^{16} \mathrm{O}_{4}$, causing the minor feature to move under the following major band. Wells et al. (2) have noted this effect, which would appear to be the primary cause of the complex structure between bands $f$ and $q$ of the $\mathrm{Os}^{16} \mathrm{O}_{4}$ spectrum. Such a complex region is noticeably absent from the $\mathrm{Os}^{18} \mathrm{O}_{4}$ spectrum.

The calculations of Cox et al. (6) suggest that, for $\mathrm{MnO}_{4}^{-}$, the observed progression is a convolution of the $a_{1}$ and $t_{2}$ metal-oxygen stretching modes, and the remarkable similarity of the $\mathrm{OsO}_{4}$ spectra suggests that the major progression of the latter should be interpreted in the same way (5). These two modes have a very similar frequency in the ground state of $\mathrm{OsO}_{4}(10,11)$. The weaker secondary features are assigned to $a_{1}$ and/or $t_{2}$ progressions built onto the electronic origin, plus one quantum of $e$ or $t_{2}$ metal-oxygen bending mode. These vibrations also have very similar frequencies in the ground electronic state $(10,11)$. The situation in both $\mathrm{OsO}_{4}$ species must, of necessity, be very similar. The qualitative differences observed in the vibronic structure of the two spectra indicate that the causes of the complexity in the $\mathrm{Os}^{16} \mathrm{O}_{4}$ spectrum are subtle and will require further work to elucidate them, but the recent work by Swift and Bernstein (7) strongly suggests that the J-T effect is the major one. In addition, there is also the problem of Coriolis interaction between $\nu_{2}$ and $\nu_{4}(11)$, which will only increase the problem. In fact, the effects of Coriolis interaction are quite difficult to predict, and further work is being done on this particular matter.

\section{ACKNOWLEDGMENT}

We acknowledge the award of a grant from NATO (1457), under whose auspices this work was done.

RECEIVED: February 16, 1984

\section{REFERENCES}

1. A. LangseTh And B. Quiller, Z. Phys. Chem. B 27, 79-89 (1934),

2. E. J. Wells, A. D. Jordan, D. S. Alderdice, AND I. G. Ross, Australian J. Chem. 20, 2315-2322 (1967). 
3. R. H. Petit, B. Briat, A. MUller, and E. DiemanN, Mol. Phys. 27, 1374-1384 (1974).

4. P. Quested, D. J. Robiins, P. DAY, ANd T. G. Denning, Chem. Phys. Lett. 22, 158-160 (1973).

5. T. J. BARTon, R. Grinter, AND A. J. ThOMSON, Chem. Phys. Lett. 40, 399-401 (1976).

6. P. A. Cos, D. J. RobBins, AND P. DAY, Mol. Phys. 30, 405-411 (1975).

7. K. M. Swift AND E. R. Bernstein, J. Chem. Phys. 74, 5981-5987 (1981).

8. J. L. Huston and H. H. ClaAssen, J. Chem. Phys. 52, 5646-5648 (1970).

9. G. DAVIDSON, N. Logan, AND A. MoRRIS, Chem. Commun. 1968, 1044-1046 (1968).

10. R. S. MCDOWELl AND M. GoldBlatT, Inorg. Chem. 10, 625-630 (1971).

11. Y. M. Bosworth, R. J. H. Clark, and D. M. RIPPON, J. Mol. Spectrosc. 46, 240-255 (1973).

12. R. Kebabicoglu and A. MÚller, Chem. Phys. Lett. 8, 59-62 (1971).

13. F. S. HAM, Phys. Rev. A 138, 1727-1740 (1965). 